\title{
Anthropometric Measurement of Hand Length, Hand Breadth and Length of Middle Finger and Their Correlation with Stature in J\&K Population
}

\author{
Dr. Mudasir Ahmad Khan ${ }^{1 *}$, Prof (Dr.) Sunanda Raina ${ }^{2}$
}

${ }^{1}$ Department of Anatomy, GMC- Srinagar Present Designation: Lecturer, Department of Anatomy, Government Medical College- Srinagar, India

${ }^{2}$ Ex-Principal \& Dean of GMC-Jammu and Ex-Head of the Department in Post-graduate Department of Anatomy, Government Medical College, Jammu, India

DOI: $10.36347 /$ sjams.2020.v08i09.003

| Received: 28.08.2020 | Accepted: 05.09.2020 | Published: 09.09.2020

*Corresponding author: Dr. Mudasir Ahmad Khan

Abstract

Original Research Article

Introduction: Stature is considered as one of the important parameters for personal identification. So, stature reconstruction is important as it provides forensic anthropological estimation of the height of a person in the living state which plays a vital role in the identification of individual remains. Aim: The aim of the present study was to investigate the association of hand length, hand breadth and length of middle finger with height and to show if height could be predicted using these measurements. Methodology: The present study was conducted on a sample of 200 medical students (100 males and 100 females) within the age group of 18-25 years from Government Medical College, Jammu and Indira Gandhi Dental College, Jammu. Results: It was observed that in males the length parameters show greater correlation than the breadth parameters and the highest correlation is shown by the Right Hand Length in males and Left Hand Length in females and lowest correlation is shown by Left Hand Breadth in males and Right Hand Breadth in females. Linear as well as multiple regression equations were also derived from each parameter studied to determine stature from them separately. Conclusion: It is concluded that dimensions of hand provides good reliability in estimation of stature. The highest correlation coefficient between stature and right hand length in males and left hand length in case of females, with lowest standard error of estimate, indicates that comparatively hand length provides highest reliability and accuracy in estimating stature in both males and females. By deriving the population specific linear and multiple regression equations, we can determine the height of a person reliably from the dimensions of hand, provided that the person belongs to the Jammu and Kashmir region.

Keywords: Stature, Hand Length, Regression, Hand Breadth, Anthropometry, Middle finger.

Copyright @ 2020: This is an open-access article distributed under the terms of the Creative Commons Attribution license which permits unrestricted use, distribution, and reproduction in any medium for non-commercial use (NonCommercial, or CC-BY-NC) provided the original author and source are credited.

\section{INTRODUCTION}

Anthropometry is a series of systematized measuring techniques that express quantitatively the dimensions of human body and skeleton [1]. Anthropometry is often viewed as a traditional and perhaps the basic tool of biological anthropology, but it has a long tradition of use in forensic sciences and it is finding increased use in medical sciences. The evidence of use of this branch of science in the field of legal medicine is available since the $19^{\text {th }}$ century, when a French police expert Mr. Alphonse Bertillon defined the system of criminal identification of individuals based on anthropometric measurements. Since then, anthropometry has continuously been used in forensic examinations of unknown commingled human remains [2]. To identify an individual, it is necessary to establish a biological profile via the estimation of age, race, sex, and stature. Also known as "big four" parameters of forensic anthropology [3]. These form the features of tentative identification [4]. By this process we can narrow down the pool of victims needed to be matched, allowing for more definitive markers, such as DNA, to be later used for the confirmation of the final identification [5]. Assessment of height from different parts of body by anthropometric study of skeleton is an area of interest to anatomists, anthropologists and forensic experts [6]. In fact, height as a measure of biological development of both an individual and a population is commonly used in physical anthropology [7]. Body Height $(\mathrm{BH})$ is anatomically complex and includes the dimensions of legs, pelvis, vertebral column and skull. The contribution of each of these to the total varies in different individuals and also in different populations. Population morphology based differences exist in the skeleton and these have changed 
over time [8]. Height estimation is also required for the assessment of growth of children, calculation of nutritional indices of children and adults for prediction and standardization of physiological parameters such as lung volumes, muscle strength, glomerular filtration, and metabolic rate and for adjustment of drug dosage in patients [9]. Nevertheless, there are some limitations for obtaining this crucial information in special clinical situations such as immobilized patients, elderly people, emergency and critically ill patients. Of these situations, visual estimation is one of the most common methods to guess patients height [10]. When intact bodies are to be examined, stature estimation does not pose any problem. But when dismembered human parts are the materials to work with, it is of great challenge. Most methods employ the basic process of comparison. Therefore, identification depends mainly upon the availability and completeness of ante-mortem records. When dealing with human remains, estimating living stature can also help to identify an unknown individual because there is a close relationship between the body part dimensions and height [11]. Estimation of stature is based on a principle that every body part bears more or less a constant relationship with height of an individual. Various studies in the past have utilized various body parts such as upper and lower extremities including hand and foot dimensions for the estimation of stature [12]. The regression formulae derived for one population does not always give accurate results for other populations [13].

In conclusion, what may be true for one race or one region may not be true for other. Even within our vast homeland of India, there are many different ethnic groups and they are having their own variations [14]. As the $\mathrm{J} \& \mathrm{~K}$ state is known to be prone to disasters like terror attacks and natural calamities, the lack of anthropometric data concerning the local population of the state was felt. This study intends to fill this lacuna and derive regression formulae from the anthropometric data taken.

\section{Material And Methods}

The present study was conducted on a sample of 200 medical students (100 males and 100 females) within the age group of 18-25 years from Government Medical College, Jammu and Indira Gandhi Dental College, Jammu.

\section{Inclusion Criteria}

Apparently healthy, asymptomatic males and females of age group 18-25 years.

\section{Exclusion Criteria}

Males and Females with physical deformities and systemic illness affecting stature and hand measurements were excluded from the study. Age group below 18 years and above 25 years were excluded from the study.

\section{Methods of Collection of Data}

The study was conducted in a separate postgraduate room. The objectives and methods of the study were explained to the sample population and informed consent was obtained, by taking their signatures on the consent form. All measurements were taken at a fixed time of day to eliminate diurnal variation. 1) Four anthropometric measurements i.e., hand length, hand breadth, length of middle finger and stature were measured. The hand measurements of both left and right side were measured separately, for each individual. 2) All the measurements were recorded with full concentration and perfection.

\section{RESULTS}

The present study was conducted on 200 subjects, 100 males and 100 females, all born and grown up in Jammu And Kashmir State. The mean age of all the subjects was 19.97 years. The mean age of males was 20.17 years and that of females was 19.77 years. The observations were made as per the proforma, especially designed to record the data. All measurements were taken on anatomical sound basis. Special attention was given to the presence of zero error in the instruments used. The observations were analyzed using PASW (SPSS) Statistics 18 Software. The observations and results were tabulated after statistical evaluation of the observations recorded in the study:

Table-1: Showing distribution of stature (in cm) among study population.

\begin{tabular}{|l|c|c|c|}
\hline & Males & Females & Total \\
\hline Number & 100 & 100 & 200 \\
\hline Mean & 172.77 & 157.92 & 165.35 \\
\hline Std. Error of Mean & 0.638 & 0.549 & 0.673 \\
\hline Std. Deviation & 6.384 & 5.495 & 9.524 \\
\hline Minimum & 157.50 & 147.00 & 147.00 \\
\hline Maximum & 188.50 & 175.00 & 188.50 \\
\hline
\end{tabular}


Table-2: Descriptive statistics of the parameters studied in Males and Females

\begin{tabular}{|c|c|c|c|c|c|c|c|c|c|c|c|c|}
\hline & \multicolumn{6}{|c|}{ Males } & \multicolumn{6}{|c|}{ Females } \\
\hline & 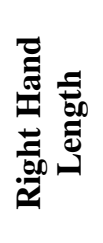 & 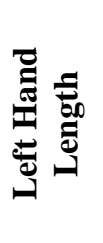 & 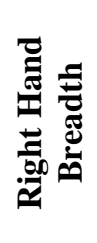 & & 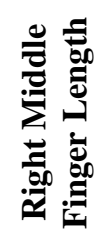 & 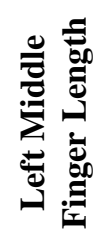 & 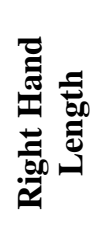 & 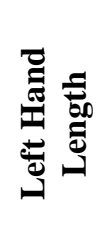 & 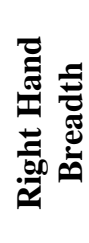 & 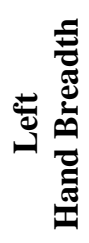 & 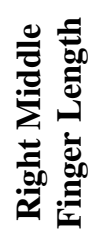 & 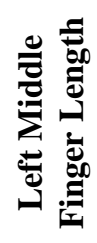 \\
\hline Number & 100 & 100 & 100 & 100 & 100 & 100 & 100 & 100 & 100 & 100 & 100 & 100 \\
\hline Mean & 18.784 & 18.759 & 8.527 & 8.429 & 8.123 & 8.101 & 17.151 & 17.088 & 7.670 & 7.570 & 7.606 & 7.571 \\
\hline $\begin{array}{l}\text { Std. Error of } \\
\text { Mean }\end{array}$ & 0.083 & 0.086 & 0.036 & 0.033 & 0.048 & 0.046 & 0.070 & 0.070 & 0.031 & 0.030 & 0.042 & 0.040 \\
\hline Std. Deviation & 0.833 & 0.865 & 0.363 & 0.337 & 0.484 & 0.461 & 0.701 & 0.704 & 0.313 & 0.300 & 0.422 & 0.403 \\
\hline & 17.00 & 16.90 & 7.80 & 7.70 & 6.90 & 7.00 & 15.50 & 15.50 & 7.00 & 6.90 & 6.60 & 6.60 \\
\hline Maximum & 21.00 & 21.00 & 9.30 & 9.30 & 9.20 & 9.20 & 19.70 & 19.70 & 8.50 & 8.50 & 9.00 & 9.10 \\
\hline
\end{tabular}

Table-3: Paired sample " $t$ " test showing statistical difference between right and left side in Males and Females

\begin{tabular}{|c|c|c|c|c|c|c|c|c|c|c|c|c|c|}
\hline & \multirow[b]{2}{*}{ Paired Samples } & \multicolumn{6}{|c|}{ Males } & \multicolumn{6}{|c|}{ Females } \\
\hline & & 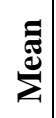 & के & & 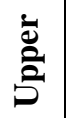 & - & 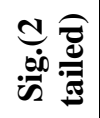 & $\stackrel{\Xi}{\Sigma}$ & $\hat{\infty}$ & 递 & 产 & - & 잉 \\
\hline Pair 1 & $\begin{array}{l}\text { Right Hand Length \& } \\
\text { Left Hand Length }\end{array}$ & $\stackrel{2}{0}$ & $\begin{array}{l}\infty \\
\frac{\infty}{0} \\
0\end{array}$ & $\begin{array}{l}\bar{\sigma} \\
0 \\
\dot{0} \\
1\end{array}$ & $\ddot{\square}$ & $\stackrel{?}{-}$ & $\stackrel{\Sigma}{\Xi}$ & $\begin{array}{l}0 \\
\stackrel{0}{0} \\
0\end{array}$ & $\begin{array}{l}m \\
\stackrel{g}{0}\end{array}$ & 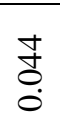 & $\begin{array}{l}\bar{\infty} \\
0 \\
0\end{array}$ & $\hat{\sigma}$ & $\begin{array}{l}\stackrel{*}{\circ} \\
\stackrel{8}{8} \\
\stackrel{0}{0}\end{array}$ \\
\hline Pair 2 & $\begin{array}{l}\text { Right Hand Breadth \& } \\
\text { Left Hand Breadth }\end{array}$ & $\begin{array}{l}\infty \\
: \\
0\end{array}$ & $\frac{7}{3}$ & $\stackrel{m}{0}$ & 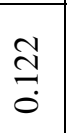 & $\stackrel{\infty}{\sim}$ & 苍 & $\frac{8}{\circ}$ & $\begin{array}{l}1 \\
\stackrel{1}{0} \\
0\end{array}$ & ڤ્) & 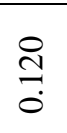 & $\hat{a}$ & 苍 \\
\hline Pair 3 & $\begin{array}{l}\text { Right Middle Finger Length } \\
\text { \& } \\
\text { Left Middle Finger Length }\end{array}$ & ָे & $\frac{\text { I }}{\stackrel{0}{0}}$ & $\begin{array}{l}8 \\
\vdots \\
\\
\end{array}$ & ஜ̂. & $\stackrel{n}{\longrightarrow}$ & $\stackrel{0}{\stackrel{0}{0}}$ & 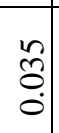 & $\frac{0}{n}$ & $\overbrace{0}^{n}$ & $\underset{0}{0}$ & $\stackrel{m}{i}$ & $\begin{array}{l}\stackrel{*}{\tilde{I}} \\
\stackrel{0}{0}\end{array}$ \\
\hline
\end{tabular}

$*$ Statistically Significant $(\mathrm{p}<0.05)$

Table-4: Shows correlation between the stature of an individual and various parameters studied in Males and Females

\begin{tabular}{|c|c|c|c|c|}
\hline \multirow{2}{*}{ Parameter } & \multicolumn{2}{|c|}{ Males } & \multicolumn{2}{|c|}{ Females } \\
\hline & $\begin{array}{l}\text { Pearson } \\
\text { Correlation }\end{array}$ & Sig. (2-tailed) & $\begin{array}{l}\text { Pearson } \\
\text { Correlation }\end{array}$ & Sig. (2-tailed) \\
\hline Right Hand Length & 0.689 & $0.000 * *$ & 0.629 & $0.000 *$ \\
\hline Left Hand Length & 0.679 & $0.000^{* *}$ & 0.652 & $0.000 *$ \\
\hline Right Hand Breadth & 0.200 & $0.047 *$ & 0.465 & $0.000 *$ \\
\hline Left Hand Breadth & 0.261 & $0.009^{* * *}$ & 0.480 & $0.000^{*}$ \\
\hline Right Middle Finger Length & 0.605 & $0.000^{* *}$ & 0.586 & $0.000 *$ \\
\hline Left Middle Finger Length & 0.591 & $0.000^{* * *}$ & 0.628 & $0.000^{*}$ \\
\hline & \multicolumn{2}{|c|}{$\begin{array}{l}\text { **. Correlation is significant at the } \\
0.01 \text { level ( } 2 \text {-tailed) } \\
\text { *. Correlation is significant at the } 0.05 \\
\text { level ( } 2 \text {-tailed) }\end{array}$} & \multicolumn{2}{|c|}{$\begin{array}{l}\text { *. Correlation is significant at } \\
\text { the } 0.01 \text { level (2-tailed) }\end{array}$} \\
\hline
\end{tabular}


Table-5: Showing Linear regression equation for various parameters studied in Males and Females

\begin{tabular}{|c|c|c|c|}
\hline \multicolumn{2}{|c|}{ Linear Regression Equations in Males } & \multicolumn{2}{|c|}{ Linear Regression Equations in Females } \\
\hline $\begin{array}{l}\text { Stature }=\text { Constant }+ \text { Regression } \\
\text { Coefficient } \\
(\text { Dimension }) \pm \text { Standard Error of } \\
\text { Estimate }\end{array}$ & $\begin{array}{l}\text { Coefficient of } \\
\text { Determination } \\
\left(\mathbf{r}^{2}\right)\end{array}$ & $\begin{array}{l}\text { Stature }=\text { Constant }+ \text { Regression } \\
\text { Coefficient } \\
(\text { Dimension }) \pm \text { Standard Error of } \\
\text { Estimate }\end{array}$ & $\begin{array}{l}\text { Coefficient of } \\
\text { Determination } \\
\qquad\left(\mathbf{r}^{2}\right)\end{array}$ \\
\hline $\begin{array}{l}\text { Stature }=73.68+5.27(\text { Right Hand Length }) \\
\pm 4.65\end{array}$ & 0.474 & $\begin{array}{l}\text { Stature }=73.42+4.92 \text { (Right } \text { Hand } \\
\text { Length) } \pm 4.29\end{array}$ & 0.395 \\
\hline $\begin{array}{l}\text { Stature }=78.80+5.01(\text { Left Hand Length }) \pm \\
4.71\end{array}$ & 0.461 & $\begin{array}{l}\text { Stature }=71.11+5.08(\text { Left Hand Length }) \\
\pm 4.18\end{array}$ & 0.424 \\
\hline $\begin{array}{l}\text { Stature }=142.91+3.50(\text { Right } \text { Hand } \\
\text { Breadth }) \pm 6.28\end{array}$ & 0.039 & $\begin{array}{l}\text { Stature }=95.52+8.13 \text { (Right } \text { Hand } \\
\text { Breadth) } \pm 4.89\end{array}$ & 0.215 \\
\hline $\begin{array}{l}\text { Stature }=131.18+4.93(\text { Left Hand Breadth }) \\
\pm 6.19\end{array}$ & 0.068 & $\begin{array}{l}\text { Stature }=91.46+8.77 \text { (Left } \text { Hand } \\
\text { Breadth) } \pm 4.84\end{array}$ & 0.230 \\
\hline $\begin{array}{l}\text { Stature }=108.01+7.97(\text { Right } \text { Middle } \\
\text { Finger Length) } \pm 5.10\end{array}$ & 0.366 & $\begin{array}{l}\text { Stature }=99.96+7.62(\text { Right } \text { Middle } \\
\text { Finger Length) } \pm 4.47\end{array}$ & 0.343 \\
\hline $\begin{array}{l}\text { Stature }=106.44+8.18 \text { (Left Middle Finger } \\
\text { Length) } \pm 5.17\end{array}$ & 0.349 & $\begin{array}{l}\text { Stature }=93.14+8.55 \text { (Left Middle Finger } \\
\text { Length) } \pm 4.30\end{array}$ & 0.393 \\
\hline
\end{tabular}

Table-6: Showing multiple regression equation for various parameters studied.

\begin{tabular}{|l|c|}
\hline \multicolumn{1}{|c|}{ Multiple Regression Equations } & $\mathbf{r}^{2}$ \\
\hline Stature $=30.24+5.93$ (Right Hand Length) +3.52 (Right Hand Breadth) \pm 4.83 & 0.745 \\
\hline Stature $=32.16+5.54$ (Left Hand Length) +4.23 (Left Hand Breadth) \pm 4.76 & 0.752 \\
\hline Stature $=37.68+7.64$ (Right Middle Finger Length)+8.33(Right Hand Breadth) \pm 5.66 & 0.649 \\
\hline Stature $=35.49+7.66$ (Left Middle Finger Length)+8.73(Left Hand Breadth) \pm 5.48 & 0.671 \\
\hline Stature $=31.02+6.34$ (Right Hand Length) +3.43 (Right Hand Breadth) -0.94 (Right Middle Finger Length) \pm 4.83 & 0.745 \\
\hline Stature $=33.09+5.92$ (Left Hand Length) +4.17 (Left Hand Breadth) -0.94 (Left Middle Finger Length) \pm 4.76 & 0.753 \\
\hline
\end{tabular}

Table-7: Showing the Minimum, Maximum and Mean of the observed value of stature and values predicted by regression equation from various parameters in Males and Females.

\begin{tabular}{|l|c|c|c|c|c|c|}
\hline \multirow{2}{*}{} & \multicolumn{3}{|c|}{ Males } & \multicolumn{3}{c|}{ Females } \\
\cline { 2 - 6 } & $\begin{array}{c}\text { Minimum } \\
(\mathbf{c m})\end{array}$ & $\begin{array}{c}\text { Maximum } \\
(\mathbf{c m})\end{array}$ & $\begin{array}{c}\text { Mean } \\
(\mathbf{c m})\end{array}$ & $\begin{array}{c}\text { Minimum } \\
(\mathbf{c m})\end{array}$ & $\begin{array}{c}\text { Maximum } \\
(\mathbf{c m})\end{array}$ & $\begin{array}{c}\text { Mean } \\
(\mathbf{c m})\end{array}$ \\
\hline $\begin{array}{l}\text { Observed Value } \\
\text { (Actual Stature) }\end{array}$ & $\mathbf{1 5 7 . 5 0}$ & $\mathbf{1 8 8 . 5 0}$ & $\mathbf{1 7 2 . 7 7}$ & $\mathbf{1 4 7}$ & $\mathbf{1 7 5}$ \\
\hline Right Hand Length & 163.36 & 184.46 & 172.75 & 149 & 170.48 \\
\hline Left Hand Length & 163.47 & 184.01 & 172.73 & 149.85 & 171.19 \\
\hline Right Hand Breadth & 170.22 & 175.48 & 172.77 & 152.47 & 164.67 \\
\hline Left Hand Breadth & 169.17 & 177.07 & 172.77 & 152.04 & 157.92 \\
\hline Right Middle Finger Length & 163.02 & 181.36 & 172.77 & 150.26 & 166.08 & 157.92 \\
\hline Left Middle Finger Length & 163.75 & 181.76 & 172.77 & 149.61 & 176.23 & 157.91 \\
\hline
\end{tabular}

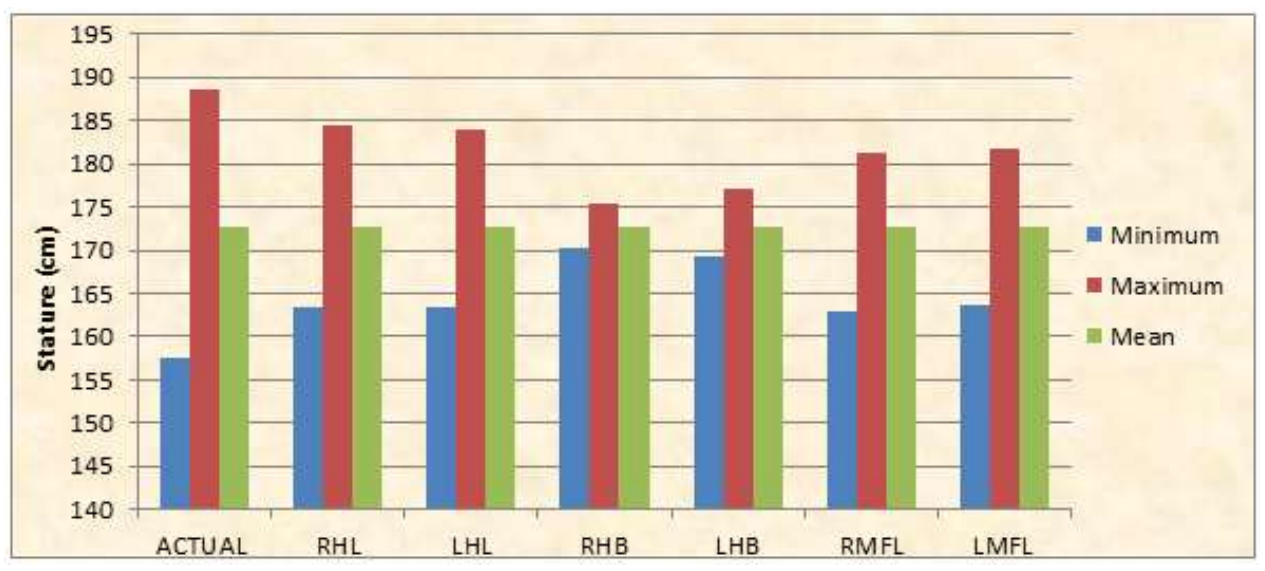

Fig-I: Depicting the comparison between observed (actual) and predicted values of stature by various regression parameters in Males 


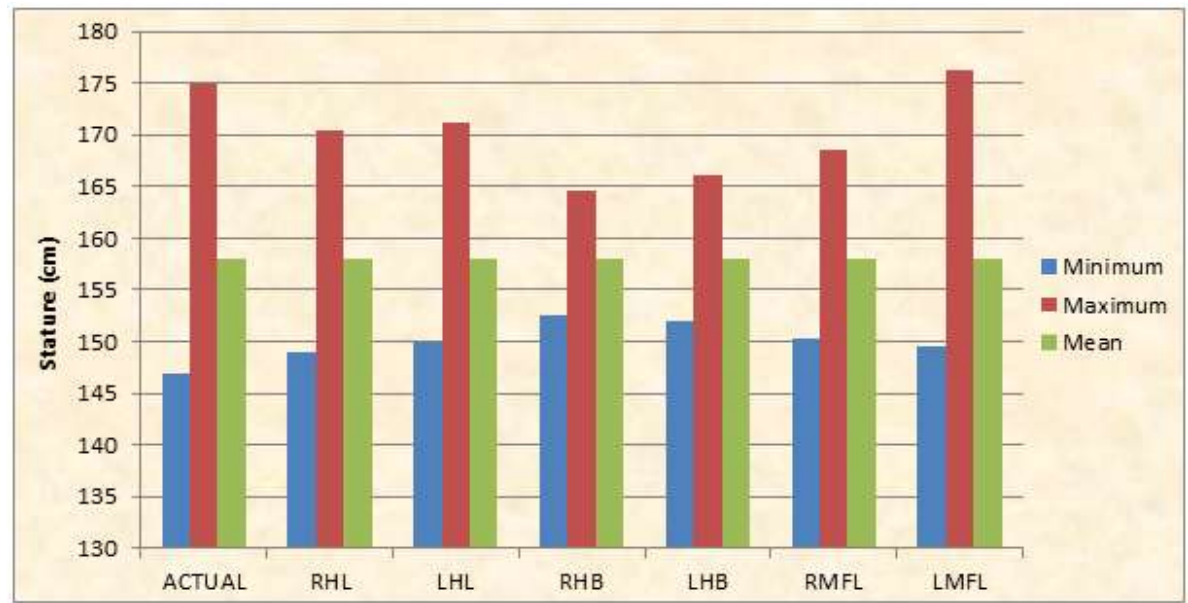

Fig-II: Depicting the comparison between observed (actual) and predicted values of stature by various regression parameters in Females

Table 1 shows distribution of stature among study population, ranging from $157.50-188.50 \mathrm{~cm}$ in males and $147-175 \mathrm{~cm}$ in females. The mean stature among males is $172.77 \mathrm{~cm}$ with the standard deviation of $\pm 6.384 \mathrm{~cm}$ and the mean stature among females is $157.92 \mathrm{~cm}$ with the standard deviation of $\pm 5.495 \mathrm{~cm}$. The overall mean stature of the population is $165.35 \mathrm{~cm}$ with the standard deviation of $\pm 9.524 \mathrm{~cm}$. Table 2 shows the descriptive statistics of various parameters studied in males. The mean hand length of 18.784 $(\mathrm{SD} \pm 0.833) \mathrm{cm}$ on right side, mean hand breadth of $8.527(\mathrm{SD} \pm 0.363) \mathrm{cm}$ on right side and length of middle finger of $8.123(\mathrm{SD} \pm 0.484) \mathrm{cm}$ on right side, all indicate that the various descriptive parameters are more on right side as compared to left side. The table also shows the descriptive statistics of various parameters studied in females. The mean hand length of $17.151(\mathrm{SD} \pm 0.701) \mathrm{cm}$ on right side, mean hand breadth of $7.670(\mathrm{SD} \pm 0.313) \mathrm{cm}$ on right side and length of middle finger of $7.606(\mathrm{SD} \pm 0.422) \mathrm{cm}$ on right side all indicate that in case of females also, the various descriptive parameters are more on right side as compared to left side. Table 3 shows the statistical analysis in the above mentioned table indicates that the bilateral variations were statistically insignificant for all the measurements except Hand Breadth which was found to be statistically significant $(\mathrm{P}<0.05)$ in males. The statistical analysis in the above mentioned table also indicated that the bilateral variations were statistically significant for all the measurements in females. Table 4 shows the correlation of stature with various other parameters studied in males. It is also observed that in males the length parameters show greater correlation than the breadth parameters and the highest correlation is shown by the Right Hand Length (0.689) and lowest correlation is shown by Right Hand Breadth (0.200). All the parameters exhibit statistically significant positive correlation with stature. The above table also shows the correlation of stature with various other parameters studied in females. It is also observed that in females also the length parameters show greater correlation than the breadth parameters and the highest correlation is shown by the Left Hand Length (0.652) and lowest correlation is shown by Right Hand Breadth (0.465). All the parameters exhibit statistically highly significant $(\mathrm{p}<0.01)$ positive correlation with stature. Table 5 shows linear regression equations predicting stature using various parameters in males. The equations also exhibit Standard Error of Estimate (SEE).The SEE predicts the deviation of estimated stature from the actual stature. It ranges between \pm 4.65 to \pm 6.28 . Lower values indicate greater reliability in the estimated stature. Right Hand Length exhibits a lower value in males and gives better reliability in prediction of stature. The table also shows the power of prediction or coefficient of determination $\left(\mathrm{r}^{2}\right)$, which is a measure of how well the variation in one variable explains the variation of the other. In case of males it is the right hand length which has the highest prediction power $\left(r^{2}\right.$ $=0.474)$ and the right hand breadth has the lowest prediction power $\left(\mathrm{r}^{2}=0.039\right)$. Table 6 presents multiple regression equations for the estimation of stature from different combination of hand dimensions. It is observed that the multiple regression equations reveal lower values of SEE $( \pm 4.76$ to \pm 5.66$)$. Suggesting that multiple regression equations are better formulae for stature estimation as compared to linear regression equations. Table 7 depicting mean predicted value of stature through the regression function, which is almost similar to the mean observed value; however the minimum and maximum value indicated that there were differences in the predicted and observed value. The difference in the minimum predicted value was around 5 to $12 \mathrm{~cm}$ and the maximum was around 4 to $13 \mathrm{~cm}$. The table also depicts in case of females the mean predicted value of stature, through the regression function, is similar to the mean observed value; however the minimum and maximum value indicated that there are differences in the predicted and observed value. The difference in the minimum predicted value was around 2 to $5 \mathrm{~cm}$ and the maximum was around 2 to $10 \mathrm{~cm}$. Using the regression equations derived in the study, regression lines have been plotted depicting a significant positive correlation between stature and hand dimensions in males, females and in total. 


\section{DISCUSSION}

Identification is the determination of individuality of a person based on certain physical characteristics i.e., exact fixation of the personality. In partial or incomplete identification, certain facts are determined e.g., race, age, sex, stature etc.

The interest in the estimation of stature for identification already existed in antiquity. The skeleton is one part of the body that resists all environmental insult for maximum time and thus, can be a valuable tool in identification. Stature is a parameter that can be estimated even in mutilated and dismembered bodies, as well as in fragmentary human remains [15].

Over many decades, a close relationship between stature and dimensions of various body segments are reported and the results are frequently used in the medico-legal investigations.

In this cross-sectional descriptive study an attempt was made to estimate stature of a person by using its hand length, hand breadth and length of middle finger of both sides. Males and females aged between 18 to 25 years, who were born and brought up in the Jammu and Kashmir state were included. Measurement of hand length, hand breadth and length of middle finger of both hands of each subject was taken. As it is not always possible to measure all the variables, so it is useful to have separate regression equations available for each variable. The prediction function was derived through linear and multiple regression equations from each parameter for both, males and females, separately.

The results of the present study showed that the dimensions of the hand can successfully be used for the estimation of stature by law enforcement agencies and forensic scientists. The only precaution to be taken into consideration is that these formulae are applicable to the population of Jammu and Kashmir, due to inherent population variations in these dimensions, which may be attributed to genetic and environmental factors like climate, nutrition etc.

In the present study males showed higher mean values in all the parameters studied, than among females and the differences in these measurements was found to be statistically significant $(p<0.001)$. Hence our findings reveal a clear pattern of sexual dimorphism with females, consistently having smaller stature, hand length, hand breadth and length of middle finger compared to their male counterparts and this is in line with the findings of earlier studies done in this regard by - Isurani et al. [16], Agrawal et al. [17] and Jethva et al. [18].

These statistical significant differences may be due to the early pubertal growth spurt in girls that stops early, under the influence of oestrogen, which causes early fusion of epiphysis. In males although the growth spurt occurs comparatively later, they continue to grow for a longer period under the influence of testosterone. This reason necessitates different equations for males and females.

The mean stature found in our study was $172.77(\mathrm{SD} \pm 6.38) \mathrm{cm}$ in males and $157.92(\mathrm{SD} \pm 5.49)$ $\mathrm{cm}$ in females. The males having greater stature than females and this difference was found to be statistically highly significant $(\mathrm{P}<0.001)$.

These results were comparable with the previous studies conducted by Abdul-Malek et al. [19], Jasuja [20] and Krishan and Sharma [21] all of them have observed that the mean stature was greater in males than females.

This suggests that the formula for one sex cannot be applied to estimate stature of the other sex.

The mean stature found by different authors in India in different regions or states is slightly different [3] and this can be explained by the different genetic constitution, environmental factors and nutrition in different population groups.

In our study we observed that the hand dimensions of the males are more than the hand dimensions of females and this difference was statistically highly significant $(\mathrm{p}<0.001)$. This finding is in agreement with various studies conducted on hand dimensions in different adult populations - Sanli et al. [22] in Turkish population; Krishan and Sharma [21] in North Indian population; Agnihotri et al. [23] in Mauritian population; also reported larger hand dimensions in males than females. Similar results were observed by Rastogi et al. [24] for the middle finger length.

Variations were also noted in the hand dimensions of same sex in different study populations. Anthropometric parameters like hand dimensions are genetically determined and hence are known to vary between different ethnic groups.

As far as bilateral asymmetry is concerned in our study, all the parameters i.e., hand length, hand breadth and length of middle finger, shows statistically significant bilateral asymmetry $(\mathrm{p}<0.05)$ in both males and females except for the hand length and length of middle finger in males, where the bilateral asymmetry was not statistically significant.

Our study is in accordance with the study conducted by Krishan and Sharma [21] and Ishak et al. [25], in which they reported that bilateral variation was statistically significant for hand breadth only. 
Our study is also in consonance with the study conducted by Abdul-Malek et al. [19], in which they demonstrated right and left differences only for hand breadth.

As far as middle finger is concerned, a study conducted by Rastogi et al. [24] observed significant differences in the measurements and formulae for males and females. These differences were statistically insignificant when values were compared between subjects of the same sex in North and South Indians and also between the dominant and non-dominant hand.

This shows that if sex and race are known and side of hand is known then stature can be estimated more precisely using any of the regression formulae.

All the parameters showed statistically significant positive correlation with stature in the present study and thus can be successfully utilized for the stature estimation.

In males right hand length with correlation coefficient of $\mathrm{r}=+0.689$ followed by left hand length with correlation coefficient of $\mathrm{r}=+0.679$, exhibits comparatively higher correlation with stature and these correlations are statistically highly significant $(p<0.001)$. The right hand breadth, with statistically significant, correlation coefficient of $\mathrm{r}=+0.200$, exhibits comparatively least correlation with stature.

Thus in males, right hand length is the best parameter for the estimation of stature followed by left hand length.

In females left hand length with correlation coefficient of $\mathrm{r}=+0.652$ followed by right hand length with correlation coefficient of $\mathrm{r}=+0.629$, exhibits comparatively higher correlation with stature and these correlations are statistically highly significant $(\mathrm{p}<0.001)$. The right hand breadth, with statistically significant, correlation coefficient of $\mathrm{r}=+0.200$, exhibits comparatively least correlation with stature.

Thus in females left hand length is the best parameter for the estimation of stature followed by right hand length.

Overall, both in males and females, it is the left hand length which exhibits, statistically highly significant, highest correlation coefficient with stature ( $\mathrm{r}$ $=+0.855)$ and the right middle finger length the least $(\mathrm{r}$ $=+0.711)$.

These observations of our study are in agreement with the study done by Ishak et al. [25], according to which the variable most strongly correlated to stature is hand length - the same relationship was explained for the left and right hand in each sex.
Our results were not in consonance with the study conducted by Modibbo et al. [26], where they observed hand breadth was having higher statistically significant correlation $(\mathrm{r}=+0.62)$ with stature as compared to hand length $(\mathrm{r}=+0.60)$. Therefore according to this study hand breadth is the best parameter to estimate stature.

Srivastava and Yadav [27] - conducted a study on 100 males and 123 females for the reconstruction of stature using hand and foot dimensions among Indian population and observed that comparatively hand length exhibits statistically significant higher correlation coefficient of $r=+0.61$ than hand breadth, $r=+0.34$, in males. While as in females it was hand breadth which was having higher correlation coefficient $(\mathrm{r}=+0.31)$ than hand length $(r=+0.30)$.

The differences in the correlation coefficient in various studies may be attributed to obvious genetic and possible environmental factors.

In our study it may be emphasized that all measurements exhibit higher values of correlation coefficient in both sexes and thus offer a reliable estimate of stature for both males and females of this region.

The presence of a positive linearity between the study variables and the stature facilitates formulation of regression equations which can be successfully utilized for the stature estimation.

Both linear and multiple regression equations were evolved and it was found that by applying these equations, minimum and maximum actual stature and the stature estimated from bilateral hand length among males and females varied but, the mean value of actual stature of males $(172.77 \mathrm{~cm})$ and stature estimated from bilateral hand length $(172.7 \mathrm{~cm})$ was almost similar. Similarly, the mean value of actual stature of females $(157.92 \mathrm{~cm})$ and stature estimated from bilateral hand length $(157.92 \mathrm{~cm})$ was same.

These findings are in accordance to the study conducted by Krishan and Sharma ${ }^{[21]}$, wherein they also observed greater variation of estimated minimum and maximum stature with respect to the actual minimum and maximum stature, but the mean value estimates were close to each other.

In order to assess the accuracy of our regression equations, the Standard Error of Estimate (SEE) was derived, which predicts the deviation of estimated stature from the actual stature. Lower the SEE value more accurate will be the regression model. In our study the SEE was lowest for the right hand length $(\mathrm{SEE} \pm 4.65 \mathrm{~cm})$ in males and in case of females it was lowest for left hand length $(\mathrm{SEE} \pm 4.18 \mathrm{~cm})$. Expectedly, other researches also demonstrated that this is the most 
accurate measurement for estimating stature, albeit their regression models have a higher accuracy: e.g. Sanli et al. [22] $\pm 3.50 \mathrm{~cm}$; Rastogi et al. [24] $\pm 3.65 \mathrm{~cm}$; Krishan and Sharma [21] $\pm 3.78 \mathrm{~cm}$. This improved accuracy may possibly be attributed to the lack of diversity in their sample populations, specifically in terms of genetic variability.

With regards to our multiple regression models for hand measurements, we demonstrated that the multiple regression equations give increased prediction accuracy with SEE ranging from $( \pm 4.76$ to \pm 5.66$) \mathrm{cm}$ compared to overall linear regression model with SEE ranging from $( \pm 4.95$ to \pm 6.71$) \mathrm{cm}$. These findings are in agreement with the studies conducted by Krishan and Sharma [21] and Sanli et al. [22]. Rastogi et al. [24] suggests that when predicting stature "...multiple regression equations give more accurate results".

The other value determined in our study is the coefficient of determination or power of prediction $\left(r^{2}\right)$, which determines the strength of association between the parameters and $r^{2} \times 100$ gives the percentile contribution of significant factors to dependent variables. It means the percentage that a dimension contributes to the variation in the dependent variable (i.e. stature).

The value of $r^{2}$ in males range from 0.039 to 0.474 , with highest value for the right hand length (0.474), which indicates that $47.4 \%$ of the prediction of stature can be attributed to the right hand length. So the highest power of prediction of stature in case of males is for right hand length.

Similarly, in case of females the value of $r^{2}$ ranges from 0.215 to 0.424 , with highest value for the left hand length (0.424), which indicates that $42.4 \%$ of the prediction of stature can be attributed to the left hand length. So the highest power of prediction of stature in case of females is for left hand length.

The coefficient of determination obtained through multiple regression models for both sexes ranges from 6.49 to 7.53 . The highest being 7.53 for left hand length + left hand breadth + left middle finger length indicating that $75.3 \%$ of prediction of stature can be contributed to these three parameters. This is in contrast to $73 \%$ by left hand length, $57.8 \%$ by left hand breadth and $53.5 \%$ for left middle finger length individually. This confirms that prediction power of regression equations taking multiple parameters is more than the linear regression equations, taking a single parameter.

These findings are in accordance with the findings of a study conducted by Abdel-Malek et al. [19], where they used multiple regression model. The coefficient of determination $\left(r^{2}\right)$ was 0.72 , which suggests $72 \%$ of variation in height could be attributed to hand length and hand breadth, out of which $68 \%$ variation in height relates to variation in hand length and only $4 \%$ relates to variation in hand breadth which means that hand length was highly predictive of stature when compared to hand breadth.

\section{Conclusion}

It is concluded that dimensions of hand provides good reliability in estimation of stature. The highest correlation coefficient between stature and right hand length in males and left hand length in case of females, with lowest standard error of estimate, indicates that comparatively hand length provides highest reliability and accuracy in estimating stature in both males and females. By deriving the population specific linear and multiple regression equations, we can determine the height of a person reliably from the dimensions of hand, provided that the person belongs to the Jammu and Kashmir region.

\section{ACKNOWLEDGEMENTS}

The author is indebted to all the students who voluntarily took part in the study.

\section{REFERENCES}

1. Krishan K. Anthropometry in forensic medicine and forensic science-'Forensic Anthropometry'. Internet J Forensic Sci. 2006;2(1).

2. Waghmare V, Gaikwad R, Herekar N. Estimation of the stature from the anthropometric measurement of hand length. The internet journal of biological anthropology. 2011;4(2).

3. Krishan K, Kanchan T, Sharma A. Multiplication factor versus regression analysis in stature estimation from hand and foot dimensions. Journal of forensic and legal medicine. 2012 May 1;19(4):211-4.

4. Vij K. Textbook of Forensic Medicine, Principles and Practice. $2^{\text {nd }}$ edition, New Delhi: Elsevier India Pvt. Ltd. 2002: 62-134.

5. Ahmed AA. Estimation of stature from the upper limb measurements of Sudanese adults. Forensic science international. 2013 May 10;228(1-3):178e1.

6. Numan AI, Idris MO, Zirahei JV, Amaza DS, Dalori MB. Prediction of stature from hand anthropometry: A comparative study in the three major ethnic groups in Nigeria. Journal of Advances in Medicine and Medical Research. 2013 Mar 22:1062-73.

7. Ahmad N, Mohammad F, Farooque I. Estimation of height from the long bones of upper limb and hand dimensions in South Indian population. J Evidence Based Med Health Care. 2014 Sep;1(7):473-8.

8. Kaur D, Shukla L, Jain S, Choudhary S. Hand: a scientific tool of measurement?. Journal of Morphological sciences. 2017 Jan 16;30(3):0-. 
9. Chawla M. The relationship between hand breadth and height in adult males of North Indian Punjabi population. Journal of Evolution of Medical and Dental Sciences. 2013 Mar 25;2(12):1880-8.

10. Chittawatanarat K, Msc SP, Trakulhoon V, Ungpinitpong W, Patumanond J. Height prediction from anthropometric length parameters in Thai people. Asia pacific journal of clinical nutrition. 2012 Sep 1;21(3):347.

11. Arun Kumar A, Soodeen-Lalloo AK. Estimation of stature from fragmented human remains. Anthropol. 2013;1(105):2.

12. Mohanty BB, Agrawal D, Mishra K, Samantsinghar P, Chinara PK. Estimation of height of an individual from forearm length on the population of Eastern India. Journal of Medical \& Allied Sciences. 2013 Aug 31;3(2):72.

13. Duyar İ, Pelin C. Estimating body height from ulna length: need of a population-specific formula. Eurasian journal of Anthropology. 2010 Feb 13;1(1):11-7.

14. Chikhalkar BG, Mangaonkar AA, Nanandkar SD, Peddawad RG. Estimation of stature from measurements of long bones, hand and foot dimensions. J Indian Acad Forensic Med. 2010;32(4):329-3.

15. Supare MS, Pandit SV, Bagul AS. Estimation of stature from hand length and hand breadth in medical students of Maharashtra, India. International Journal of Health \& Allied Sciences. 2015 Jul 1;4(3):154.

16. Isurani I, Nanayakkara $G$ and Palahepitiya $N$. Prediction of personal stature based on the hand length. Galle Medical Journal. 2009; 14(1): 15-18.

17. Agrawal J, Raichandani L, Kataria SK and Raichandani S. Estimation of stature from hand length and length of phalanges. Journal of evolution of medical and dental sciences. 2013; 2(50): 9651-9656.

18. Jethva N, Patel SV, Patel SM, Vora R and Purmar G. Estimation of stature from hand length in living subjects of Gujarat region. National Journal of
Integrated Research in Medicine. 2013; 4(4): $57-$ 60.

19. Abdul-Malek AK, Ahmed AM, EL-Sharkawi SA and EL-Hamid NA. Prediction of stature from hand measurements. Forensic Science International. 1990; 46: 181-187.

20. Jasuja OP and Singh G. Estimation of stature from hand and phalange length. Journal of Indian Academy of Forensic Medicine. 2004; 26(3): 100106.

21. Krishan K and Sharma A. Estimation of stature from dimensions of hand and feet in a North Indian population. Journal of Forensic Legal Medicine. 2007; 14(6): 327-332.

22. Sanli SG, Kizilkanat ED, Boyan N, Ozsahin ET, Bozkir MG, Soames R, Erol H and Oguz O. Stature estimation based on hand length and foot length. Journal of Clinical Anatomy. 2005; 18(8): 589 596.

23. Agnihotri AK, Agnihotri S, Jeebun $\mathrm{N}$ and Googoolye K. Prediction of stature using hand dimensions. Journal of Forensic Legal Medicine. 2008; 15(8): 479-482.

24. Rastogi P, Kanchan $\mathrm{T}$, Menezes $\mathrm{R}$ and Yogamarasimla K. Middle finger length a predictor of stature in Indian population. Medical Science Law. 2009; 49(2): 123-126.

25. Ishak NI, Hemy $\mathrm{N}$ and Franklin D. Estimation of stature from hand and handprint dimensions in a western Australian population. Forensic Science International. 2012; 216(1-3): 199e1-7.

26. Modibbo MH, Taura MG, Agu OC and Bashir U. Estimation of stature from hand and foot dimensions in Hausa Neonates: A hospital based study. Bayero Journal of Applied Sciences. 2012; 5(2): 110-114.

27. Srivastava A and Yadav VK. Reconstruction of stature using hand and foot dimensions among Indian population. International Journal of Engineering Sciences and Emerging Technologies. 2014; 6(4): 400-404. 